\title{
LA NATURALEZA DE LA CONSCIENCIA
}

\author{
IGNACIO MORGADO BERNAL \\ Instituto de Neurociencia \\ Universidad Autónoma de Barcelona
}

\begin{abstract}
RESUMEN. La consciencia es un estado unificado de la mente, cualitativo y subjetivo. Una de cuyas formas más especiales es la autoconsciencia, que nos permite darnos cuenta de que nos damos cuenta y reflexionar sobre nuestros propios pensamientos (sección 1). Esta consciencia dota al ser humano de la capacidad para interpretar el mundo y responder a él. Así, gracias a los qualia, tenemos la capacidad de comportarnos circunstancialmente (sección 2). Es importante conocer los correlatos y las causas cerebrales que dan origen a la consciencia. Es en la corteza cerebral donde radica la capacidad de ser consciente. Problema de la unidad de percepción: sincronización de neuronas o integración funcional (sección 3). Sin embargo, el problema de la consciencia no consiste sólo en conocer su naturaleza (material), sino también en conocer cómo se produce la emergencia de la imaginación subjetiva, respuesta que actualmente no existe y que tampoco aportaría ninguna ventaja práctica a la especie (sección 4).
\end{abstract}

PALABRAS CLAVE: consciencia, autoconsciencia, qualia, corteza cerebral, tálamo, sincronización de neuronas, integración de información neuronal, emergencia.

\section{The nature of consciousness}

ABSTRACT. Consciousness is a unified state of mind, a qualitative and subjective state. And one of its most special forms is self-awareness, which allows us to be aware that we are aware and reflect on our own thoughts (section 1). This consciousness endows the human being with the ability to interpret the world and also respond to it. Thus (therefore), thanks to qualia, we have the ability to behave according to the circumstances (section 2). It is important to know the brain correlates and causes that give rise to consciousness. The capacity to be conscious lies in the cerebral cortex. The unity of perception might be related to the synchronization of neurons or functional integration (section 3). However, the problem of consciousness is not only to know its nature (material), but also to know how the emergence of the subjective imagination occurs, question for which no answer exists at the moment and even if it did it would not have any practical benefit for the species (section 4).

KEY WORDS: consciousness, self-awareness, qualia, cerebral cortex, thalamus, neuronal synchronization, integration of neuronal information, emergence.

\section{QuÉ ES LA CONSCIENCIA}

La consciencia es un estado de la mente, aquello que perdemos cuando dormimos o nos anestesian. Del mismo modo que el agua puede presentarse en varios estados (sólido, líquido o gaseoso), la mente puede presentarse en estado consciente o inconsciente. Muchos procesos mentales tienen lugar de modo automático e inconsciente, pero la mayoría de ellos, como la percepción, la memoria, las motivaciones y las emociones o el lenguaje, tienen también lugar de manera consciente. La consciencia es un estado unificado porque, aunque su contenido incluya percepciones diferentes (color, forma, sonido, movimiento, olor, etc), se nos presenta siempre como un todo integrado, de tal modo que somos conscientes o no lo somos, pero nunca, salvo en casos 
excepcionales, tenemos la impresión de tener más de una consciencia al mismo tiempo. Asimismo, aunque se ha demostrado que el cerebro procesa los diferentes tipos de estímulos sensoriales y sus cambios a diferente velocidad y que ese procesamiento precede en milisegundos a su percepción consciente, esta última, lejos de resultar fragmentada, es normalmente coherente y continua.

Simplificando, podemos considerar el estado consciente como un único escenario teatral con las cortinas abiertas donde en cada momento pueden tener lugar diferentes y variadas representaciones. La inconsciencia llega cuando las cortinas se cierran. La consciencia es además un estado cualitativo, muy diferente al estado inconsciente, y un estado subjetivo porque sólo puede acceder al mismo el propio sujeto que lo percibe. Para ser conscientes no necesitamos ser especialmente estimulados ni forzar el pensamiento y aunque es cierto que la atención está muy relacionada con la consciencia y puede influir en ella, atención y consciencia no son la misma cosa pues podemos ser conscientes sin prestar atención a nada particular, como cuando descansamos relajados con los ojos cerrados, o atender y estar pendientes de cosas sin necesidad de ser conscientes de ellas, como cuando conducimos atendiendo automáticamente a la carretera mientras pensamos en lo que haremos al llegar al destino.

Una forma muy especial de consciencia es la llamada autoconsciencia o metaconsciencia, es decir, el ser conscientes de que somos conscientes, el darnos cuenta de que nos damos cuenta y poder reflexionar sobre nuestros propios pensamientos. La autoconsciencia permite que una persona que, por ejemplo, siente dolor, pueda estar preocupada por ese dolor y sus causas o consecuencias. No parece posible que ningún animal inferior sea capaz de algo semejante, pues nadie imagina a un perro o un gato reflexionando sobre su propia mente y sus propios pensamientos. Hay quien cree que animales como los chimpancés o los delfines, al existir pruebas de que podrían reconocerse a sí mismos en un espejo, tienen también capacidad de autoconsciencia, cosa que no ha podido todavía demostrarse de un modo convincente.

Un aspecto central a la autoconsciencia es el sentido de estar localizado dentro del propio cuerpo, pues cada uno de nosotros nos sentimos ubicados en los límites físicos del mismo. Ahora sabemos que ese sentido depende de la combinación consciente de nuestras percepciones sensoriales, las visuales y somáticas especialmente. Determinadas drogas, los ataques cerebrales (apoplejías) o las convulsiones resultantes de algunas enfermedades pueden alterar ese sentido y crear en los individuos percepciones extracorpóreas, es decir, el sentimiento de estar ubicado fuera de ti mismo, fuera de tu propio cuerpo, y contemplarlo desde la perspectiva que lo haría otra persona. Esto ha sido recientemente demostrado en experimentos de laboratorio incluso con individuos sanos, haciendo que mediante instrumentos ópticos especiales visualicen imágenes distantes de ellos mismos tomadas con cámaras de video al tiempo que se tocan simultáneamente el cuerpo del propio individuo y el cuerpo virtual que está viendo a través de los oculares. En esas circunstancias 
el individuo se percibe a sí mismo en la distancia, más allá de donde realmente está su cuerpo (vive sin vivir en él mismo).

\section{Para qué sirve la consciencia}

La consciencia dota a los humanos de una extraordinaria capacidad para interpretar el mundo y responder a él. Eso lo entendemos bien cuando consideramos que la alternativa a la mente consciente seria un individuo robotizado, dotado de una gran cantidad de mecanismos automáticos inconscientes (zombis) para responder a cada una de las diferentes situaciones que tuviera que afrontar a lo largo de su vida. Pero aún así, ese individuo no tendría toda la capacidad de un ser consciente para interpretar el mundo y responder flexiblemente a sus novedades e incertezas. Veamos por qué.

Cada cosa de la que somos conscientes, sea simple o compleja, tiene una determinada característica, un modo particular de ser percibida, diferente a cualquier otra. No es lo mismo percibir la rojez del rojo que el picante del picor, lo doloroso del dolor que la emoción de un premio, el sabor de una comida que el malestar de la envidia, el sentir que uno es una persona que el estar enamorado, el vivir la realidad presente que el recordarla más tarde, etc. Cada una de ellas es una percepción única y subjetiva, que sólo puede sentir quien la tiene, la primera persona. Hasta un gato, o un cocodrilo, como cualquier otro animal, deben tener una percepción particular de ser lo que son y no otra cosa. ¿Cómo será sentirse gato? ¿Será muy diferente a sentirse persona? Pues bien, a esos contenidos o cualidades subjetivas de cada experiencia consciente particular es a lo que los filósofos llaman qualia (quale en singular) y su importancia radica en que sirven para integrar una gran cantidad de información en una única percepción instantánea. El quale o percepción particular que nos produce, por ejemplo, la imagen de una persona, es una forma sintética e inmediata de informarnos, sin tener que pensar o razonar sobre ello, de todo lo que sabemos sobre esa persona en particular y sobre las personas en general, además de informarnos también de todo lo que no es esa persona (por ejemplo, otra persona, un animal o un objeto). Esa integración de información que proporcionan los qualia nos permite tomar decisiones o actuar en consecuencia sin tener que perder tiempo en analizar en detalle o profundidad la situación percibida. Tal como afirma el profesor Christof Koch, del California Instituto of Technology, la consciencia es un resumen de la realidad con carácter ejecutivo. Es decir, gracias a los qualia tenemos una extraordinaria flexibilidad para comportarnos del modo más conveniente en cada circunstancia, algo de lo que carecen los robots y otros automatismos reflejos.

Es importante tener también en cuenta que la consciencia no es información directa sobre el procesamiento físico-químico de información que tiene lugar en el cerebro, el cual que ocurre de forma totalmente inconsciente. Lo que la consciencia aporta a su modo es el resultado, el producto final de ese procesamiento, igual que lo que vemos en la pantalla de un televisor es 
una forma de presentar el resultado final de las complejas computaciones y tratamiento de la información que tiene lugar en sus circuitos electrónicos. Es normal, por tanto, como muestran algunos experimentos electrofisiológicos, que el procesamiento de información en el cerebro pueda preceder a la propia consciencia, aunque sea sólo en pocos milisegundos, del mismo modo que es normal que la electricidad pase por el cable antes de que se encienda la bombilla.

\section{Cómo El CEREBRo GENERA LA CONSCIENCIA}

$\mathrm{Al}$ investigar la naturaleza de la consciencia nos proponemos antes que nada conocer sus correlatos y causas cerebrales, es decir, las estructuras y dinámica cerebrales que la hacen posible. Comenzamos entonces por preguntarnos si la consciencia emerge de la actividad global del cerebro, de alguna estructura particular del mismo o de determinados circuitos neurales. Algo que parece descartado por falta de pruebas es que la consciencia pudiera radicar en el nivel subatómico, es decir, en las partículas que integran los átomos y moléculas de las diferentes sustancias bioquímicas del contenido o la estructura de las neuronas.

Los experimentos consistentes en desactivar un hemisferio cerebral mediante la inyección de una sustancia anestésica en la arteria carótida del mismo lado, así como las observaciones clínicas en individuos a los que, para aliviar sus crisis epilépticas, se les han seccionado las fibras nerviosas que comunican entre si los dos hemisferios cerebrales (el llamado cuerpo calloso), muestran que cada hemisferio por separado puede mantener su propio grado de consciencia y originar incluso comportamientos incompatibles entre ambas mitades del cuerpo. La corteza prefrontal, la parte más evolucionada del cerebro y relacionada estrechamente con la capacidad de pensar, razonar, planificar el futuro y tomar decisiones, tampoco parece absolutamente necesaria para que seamos conscientes pues los individuos que han sufrido traumas o accidentes que han dañado esta parte de sus cerebros siguen siendo individuos conscientes, aunque tengan alterada su capacidad de razonamiento.

Quien más se ha relacionado tradicionalmente con la consciencia es el tálamo, una estructura que se localiza en cada hemisferio en el centro del cerebro. El tálamo recibe información de los órganos sensoriales (ojos, oídos, gusto, tacto) y reenvía esa información algo transformada a la corteza cerebral. Recibe a su vez abundantes proyecciones nerviosas desde la propia corteza cerebral, estando por tanto conectado con ella de manera recíproca. El tálamo y sus abundantes proyecciones nerviosas bidireccionales con la corteza cerebral son la única parte del cerebro que no puede dañarse gravemente sin que se pierda la consciencia. Al tálamo se le llamado «el umbral de la consciencia», creyendo que hasta que la información procedente de los órganos de los sentidos no llega al mismo no empieza a hacerse consciente. Sin embargo, cuando nos anestesian se desactiva antes la corteza cerebral que el tálamo, el cual puede seguir algún 
tiempo activado incluso cuando ya estamos totalmente inconscientes. Parece entonces que la capacidad de ser consciente radica sobre todo en la corteza cerebral, aunque el tálamo puede tener un papel importante en el proceso, como veremos más adelante. Quizá por eso, un paciente que llevaba seis años en estado vegetativo inconsciente pudo recuperar la consciencia cuando se estimuló eléctricamente su tálamo en el quirófano.

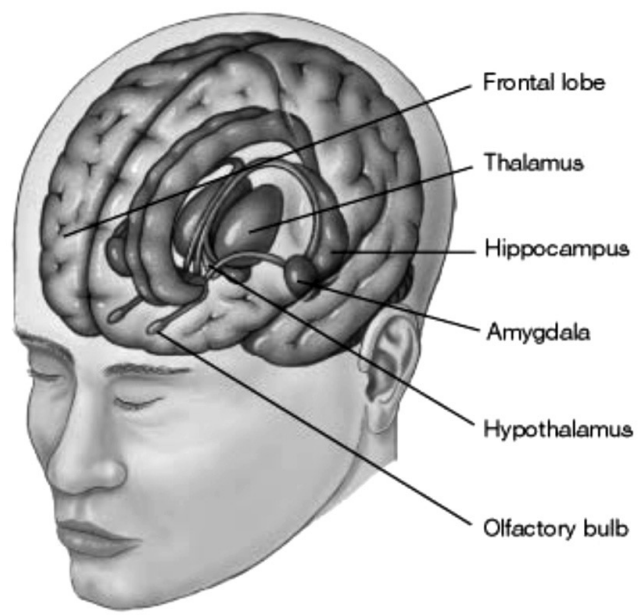

El tálamo (tono oscuro), en cada hemisferio, en el centro del cerebro

Las neuronas de la corteza cerebral están abundantemente interconectadas, lo que permite establecer numerosos circuitos de comunicación redundante entre ellas. Se ha sugerido entonces que el estado consciente podría requerir actividad recurrente (reververante, repetitiva) desde las neuronas de áreas superiores a las inferiores de procesamiento de información en la corteza cerebral y el tálamo. De ese modo, una percepción no se haría consciente hasta que el resultado de su procesamiento en determinadas estructuras superiores no rebotase y volviese hacia las estructuras inferiores que lo originaron. Esta idea, aunque no explica algunas características importantes de la consciencia, como, por ejemplo, su unicidad, se ha visto apoyada por los resultados de experimentos electrofisiológicos con monos que muestran que cuando el animal no es consciente de una imagen que se presenta muy brevemente ante sus ojos, la información neuronal de esa imagen, aunque puede alcanzar en algún grado las áreas superiores de procesamiento visual (corteza inferotemporal), no tiene capacidad para producir otra información recurrente hacia las áreas inferiores de la misma (corteza estriada), cosa que sí ocurre cuando la misma imagen se presenta durante más tiempo y el mono da pruebas de que es consciente de ella apretando un botón y recibiendo a cambio un trozo de fruta o un sonido agradable. 


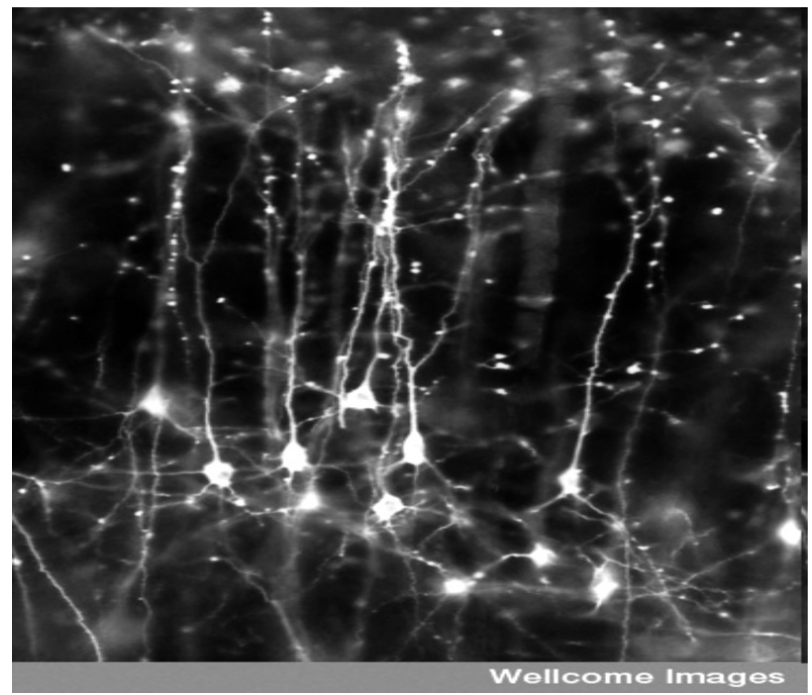

Las neuronas de la corteza cerebral están muy interconectadas, formando circuitos reververantes

Por otro lado, para resolver el problema de la unidad de la percepción consciente se han propuesto dos hipótesis. Una de ellas dice que los resultados del procesamiento neuronal de las diferentes características de un estímulo (color, forma, sonido, movimiento...etc) que tiene lugar en diferentes áreas cerebrales podrían reunirse en un lugar final común capaz de integrar toda la información recibida, algo así como una estación final adonde llegarían todos los trenes que vienen de lugares diferentes. Sin embargo, nunca se ha podido hallar tal lugar en el cerebro, por lo que los científicos han sugerido que la unidad perceptiva podría lograrse no reuniendo sino sincronizando la actividad de las neuronas de las diferentes áreas de la corteza cerebral. La metáfora para explicarlo podría ser una orquesta sinfónica. Cuando los músicos se preparan para una actuación afinando cada uno de ellos sus instrumentos por separado lo que oímos son sonidos diferenciados y dispersos, sin armonía, como formando parte de melodías múltiples y diferentes. Pero cuando los diferentes instrumentos suenan de manera sincronizada siguiendo la partitura y bajo la batuta del director lo que percibimos es una única y armoniosa melodía. De modo semejante, la actividad de las neuronas de las diferentes regiones cerebrales que procesan diferentes características de los estímulos podría originar una percepción consciente unificada cuando resulta sincronizada por algún mecanismo del propio cerebro. Es decir, la sincronización podría ser parte del mecanismo que nos permite unificar las diferentes características de un estímulo en una percepción consciente única e integral, el llamado binding perceptivo. El principal apoyo para esta teoría es que cuando los individuos son conscientes su electroencefalograma detecta una actividad sincronizada 
de frecuencia próxima a los 40 herzios (ondas gamma) en amplias regiones de la corteza cerebral. El neurólogo colombiano Rodolfo Llinás ha sido uno de los principales proponentes de que esa frecuencia de actividad sincronizada podría ser necesaria para que el cerebro pueda generar la consciencia.

Giulio Tononi, de la universidad de Wisconsin (EEUU), uno de los investigadores que más ha trabajado en el tema, tiene una idea diferente aunque quizá complementaria, pues propone que la clave de la consciencia podría radicar en la integración funcional de la actividad de los módulos o circuitos neuronales de la corteza especializados en procesar diferentes características o tipos de información, los cuales, como sabemos, no son necesariamente fijos ni adyacentes en la corteza cerebral, pudiendo cambiar en composición con la experiencia y el tiempo, pues son plásticos. La integración podría basarse en un aumento de la conectividad entre las neuronas de esos circuitos, para lo que podría ser necesaria la influencia sobre las mismas del tálamo, particularmente de las neuronas de sus núcleos intralaminares, y/o de las neuronas que también proyectan a la corteza cerebral desde diferentes núcleos del tronco del encéfalo (los llamados sistemas de arousal cortical). Tales influencias, por tanto, podrían ser necesarias para la reducción de los umbrales de activación de las neuronas de la corteza cerebral que permitiría aumentar su conectividad e integración haciendo posible el estado consciente. Serían por tanto condición necesaria, aunque no suficiente para la misma. En cualquier caso, todo parce indicar que sin la influencia de las proyecciones tálamo-corticales, aunque podría haber activación cortical (arousal), no sería posible la integración de esa actividad ni, por tanto, el estado consciente.

La metáfora para la teoría de la integración funcional sería un poliedro cuyos numerosos lados representan los diferentes módulos funcionales que son integrados, cada uno de ellos relacionado con un determinado contenido consciente. La rotación del poliedro para caer o descansar sobre cualquiera de sus lados sería el equivalente a la manifestación del contenido de la consciencia representado en ese particular lado. El cambiar de pensamiento consciente equivaldría entonces a ir girando el poliedro, y su facilidad y rapidez de giro se correspondía con la facilidad y rapidez con que puede cambiar de momento a momento el contenido de la consciencia. Pero el estado consciente sólo seria posible en la medida en que los módulos permaneciesen funcionalmente integrados. La desintegración del poliedro, con cada uno de sus lados separados del resto, sería equivalente a la desintegración funcional de los módulos, lo que llevaría a la pérdida de la consciencia. Asimismo, cualquier causa (convulsiones, fármacos, drogas, etc) que bloquease o desestabilizase la actividad normal del cerebro o de alguna de sus regiones podría reducir la información disponible (el número de módulos) para ser integrada y, de ese modo, el grado de consciencia posible. En ratas y también en humanos se ha observado que, durante el sueño, quizá por la desactivación de los sistemas de arousal del tronco del encéfalo, y cuando los sujetos son anestesiados, las neuronas de la corteza cerebral y del tálamo alteran su actividad dificultando la integración de la actividad neural que haría posible la consciencia. 

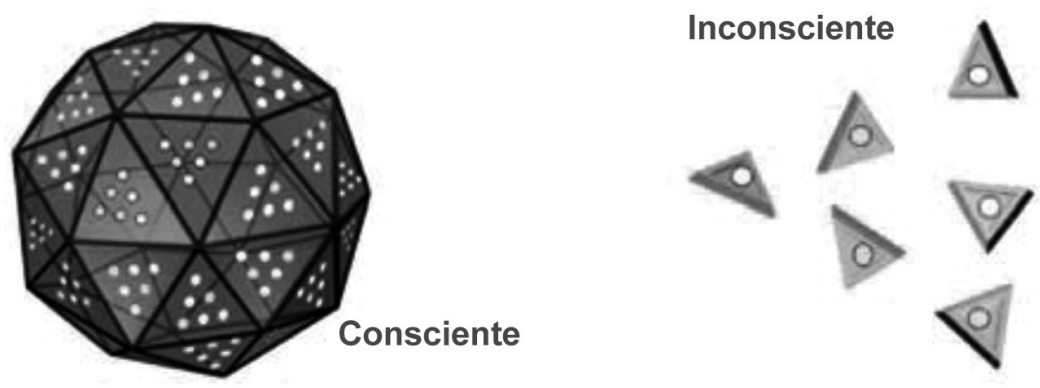

La teoría de la integración es heurística en la medida en que no sólo explica el carácter unificado de la percepción consciente, sino que explica también por qué la consciencia se nos presenta en grados diferentes según el momento. Esos grados podrían relacionarse con la cantidad de información que el cerebro integra en cada uno de esos momentos, sumando lados al poliedro. No es descartable por tanto que los diferentes sistemas de arousal cortical radicados en el tronco del encéfalo (colinérgico, dopaminérgico, histaminérgico, serotonérgico, etc) pudieran influir diferencialmente sobre la cantidad de información que la corteza integra en un momento determinado y, con ello, determinar el grado o incluso la cualidad de cada percepción consciente. La teoría de la integración funcional explica también el menor grado de consciencia que pueden tener los animales inferiores, pues su cerebro, al ser menos evolucionado, sólo permite integrar una limitada cantidad de información, muy inferior a la del cerebro humano.

Los investigadores han hallado pruebas a favor de tal integración en experimentos con neuroimágenes funcionales donde se ha observado que la actividad cerebral que origina la percepción consciente de una palabra se extiende a muchas regiones cerebrales mientras que las que genera la misma palabra cuando al estar enmascarada no es conscientemente percibida se restringe a regiones mucho menos amplias. Otra prueba importante viene de experimentos en los que se estimula magnéticamente una parte del cerebro de individuos mientras se registra electroencefalográficamente la actividad de su cerebro. Se observa de ese modo que cuando se aplica mientras el sujeto está despierto y consciente la activación neuronal magnéticamente inducida se extiende ampliamente en la corteza cerebral, pero se restringe a la zona estimulada si se le administra al sujeto cuando está dormido e inconsciente.

\section{CÓMO LA MATERIA OBJETIVA SE VUELVE IMAGINACIÓN SUBJETIVA}

Muchos científicos creen que la naturaleza de la consciencia es el principal problema que la moderna Biología tiene aún por resolver. Ello es debido a que 
el problema de la consciencia no se agota en el conocimiento de los circuitos y la actividad cerebrales que la hacen posible, pues lo que más nos intriga a los científicos es conocer cómo tiene lugar la emergencia o cambio cualitativo que convierte la actividad cerebral en qualia, es decir, cómo son posibles las diversas experiencias o percepciones conscientes, reales o ilusorias, que invaden nuestra mente. Es el llamado hard problem o problema difícil de la consciencia, frente al soft problem, que se limita a estudiar sus correlatos y/o causas cerebrales tal como hemos hecho en el apartado anterior.

Pero, cuando nos preguntamos sobre cómo la actividad cerebral genera la experiencia consciente, los qualia, ¿qué tipo de respuesta estamos esperando? Trate el lector de pensar sobre ello y responderse a sí mismo, ¿cómo entender el cambio cualitativo del fenómeno fisiológico al fenómeno mental, la emergencia de la imaginación subjetiva a partir de la materia objetiva?, ¿qué podemos esperar, en definitiva, para explicar el fenómeno psíquico de la consciencia? ¿Acaso algoritmos informáticos o fisiológicos?, ¿nos conformaríamos con una explicación basada en una fórmula matemática, nuevas partículas físicas o una forma de energía hasta ahora desconocida? Tal vez no, pues cada una de las posibles respuestas podría ser insuficiente y generar nuevas preguntas. En realidad, siendo la consciencia un fenómeno tan genuino y especial, quizá antes que nada debamos preguntarnos si podemos concebir o puede existir algún tipo de explicación inteligible sobre su naturaleza capaz de satisfacer plenamente nuestro interés científico. El propio Nóbel Francis Crick se planteaba esa misma cuestión de este modo: ¿pueden los qualia ser explicados por lo que conocemos de la ciencia moderna? Personalmente, yo dudo de que sepamos lo que estamos buscando cuando estudiamos la naturaleza íntima de la consciencia. Creo, en realidad, que no lo sabemos.

Cuando intentamos explicarla, podemos decir que hablar de la consciencia es como hablar de la relación entre el cerebro y la mente y en ese sentido una de las metáforas más utilizadas es la que afirma que de la misma manera que la temperatura no es más que la cinética o velocidad de movimiento de las partículas que integran un cuerpo, la consciencia debería ser lo mismo que la actividad fisiológica cerebral que la hace posible, y punto. Es decir, lo mismo visto desde otra perspectiva. Pero no resulta fácil conformarse con esa explicación, porque, aunque la temperatura que evalúa un termómetro sea simplemente una manera macroscópica de observar el movimiento de las partículas, el cerebro, a diferencia del termómetro, no sólo evalúa, sino que convierte el resultado de la evaluación en una nueva experiencia muy especial que llamamos calor. Podemos decir entonces que el calor no es otra cosa que el modo que tiene nuestro cerebro de percatarse del movimiento de las partículas de un cuerpo, pero seguimos sin explicar la especificidad de esa experiencia o percepción consciente. Cualquier otra metáfora podría remitirnos a la propia consciencia sin explicarnos su naturaleza.

¿Hay entonces una solución posible para el problema de la consciencia? Yo creo que actualmente no la hay, e intentaré explicar por qué mediante otra metáfora. Para preparar una comida sabrosa necesitamos una buena receta, 
adecuados ingredientes y conocer la correcta secuencia y temporalidad para cocinarlos. Pero, ¿aportaría algo al resultado conocer cómo la combinación de ingredientes y el cocinado originan el sabor del producto final? ¿Podría ese conocimiento mejorar el sabor de lo cocinado? ¿Le aportaría alguna nueva propiedad, ventaja o utilidad práctica? Probablemente no. Es decir, a priori parece más relevante y necesario conocer los ingredientes y la mezcla precisa que hacen posible un sabor que determinar la naturaleza del propio sabor como fenómeno mental consciente. Pues del mismo modo creo que, aunque pudiéramos concebir e incluso conocer alguna explicación convincente sobre cómo la fisiología inconsciente se convierte en psique consciente y en qué consiste esta última, ese conocimiento no serviría para nada más que para satisfacer nuestra curiosidad científica, sin aportar ninguna ventaja práctica.

Y esa es para mí la clave dado que, a lo largo de la evolución, la selección natural tiende a promover cosas útiles, cosas que sirvan para una mejor adaptación de los organismos a su medio. De ese modo, aunque conocer los mecanismos del cerebro que hacen posible la consciencia es algo que podemos lograr científicamente y que tendrá sin duda consecuencias prácticas en la clínica o la educación, conocer la naturaleza íntima de la subjetividad, aparte de satisfacer, como decimos, nuestra curiosidad científica, sería de ninguna o poca utilidad práctica. Quizá esa es la razón por la que la selección natural puede no haber promovido el desarrollo suficiente del cerebro humano que haga posible la comprensión de la naturaleza de la consciencia. Del mismo modo que un chimpancé no tiene un cerebro capacitado para entender una raíz cuadrada o el concepto de entropía, el cerebro humano no estaría capacitado para entender la emergencia de la consciencia. Ésta fue promovida por la selección natural en respuesta a los cambios y desafíos que se produjeron en determinados momentos de la evolución en el entorno de los animales como un medio para favorecer su adaptación a esos cambios o desafíos. Para sobrevivir los animales tuvieron que desarrollar flexibilidad mental y conductual, que es lo que proporciona la consciencia. Nuestra capacidad cerebral para entender la naturaleza de la mente consciente evolucionará cuando nuevas condiciones o desafíos ambientales hagan verdaderamente necesario ese entendimiento, aunque también es posible que entonces surjan nuevas y difíciles cuestiones que podrían ser el precio de tal promoción.

\section{REFERENCIAS}

Edelman, G.M., Gally, J. A., y BaArs, B. J., «Biology of consciousness», in Frontiers in Psychology, January 2011, Volume 2

Morgado, I., Cómo percibimos el mundo, una exploración de la mente y los sentidos, Ariel, 2011

Morgado, I., «¿Es la consciencia un epifenómeno?», en: Claves de razón práctica, $\mathrm{n}^{\circ} 230$, 2013, págs. $124-131$ 
Morgado, I., «Psicobiología de la consciencia: conceptos, hipótesis y observaciones clínicas y experimentales», en: Revista de neurología, vol. 49, nº . 5, 2009, págs. 251-256 Morgado, I., «¿Qué es la mente? ¿Cómo surgió? ¿Cómo nos hace inteligentes y sociales?», en: Psicobiología: de los genes a la cognición y el comportamiento / coord. por Ignasi Morgado Bernal, 2005, págs. 224-228

Instituto de Neurociencia

Ignacio Morgado Bernal

Universidad Autónoma de Barcelona

Ignacio.Morgado@uab.es

[Artículo aprobado para publicación en diciembre de 2016] 